Journal of

Cardiology and Vascular Medicine

\title{
Neutralization of N-half Osteopontin Prevents Atherosclerotic Plaque Rupture in
} ApoE-/-Mice

Akiko Tanino ${ }^{1}$, Takafumi Okura ${ }^{2 *}$, Jun Irita ${ }^{1}$, Tomoaki Nagao ${ }^{1}$, Mie Kurata $^{3}$, Jun Suzuki ${ }^{1}$, Masayoshi Kukida ${ }^{1}$, Ken-ichi Miyoshi ${ }^{1}$

${ }^{1}$ Department of Cardiology, Pulmonology, Hypertension and Nephrology, Ehime University Graduate School of Medicine, Ehime, Japan

${ }^{2}$ Department of Community and Emergency Medicine, Ehime University Graduate School of Medicine, Ehime, Japan ${ }^{3}$ Department of Pathology, Division of Pathogenomics, Ehime University Graduate School of Medicine, Ehime, Japan

*Corresponding author: Takafumi Okura, Department of Community and Emergency Medicine, Ehime University Graduate School of Medicine, Toon City, Ehime, 791-0295, Japan, Tel: +81-89-960-5540, Fax: +81-89-960-5890, Email: okura@m. ehime-u.ac.jp

Received Date: August 24, 2018; Accepted Date: September 11, 2018; Published Date: September 13, 2018

Citation: Akiko Tanino (2018) Neutralization of N-half Osteopontin Prevents Atherosclerotic Plaque Rupture in ApoE-/-Mice. J Cardio Vasc Med 4: 1-10.

\section{Abstract}

Aims: Atherosclerosis is chronic inflammation of arteries, andosteopontin (OPN) is known to play a significant role in atherosclerotic inflammation. Thrombin cleaves OPN, resulting in the formation of a N-terminal fragment (N-half OPN) that enhances inflammation during atherosclerosis. We hypothesized that N-half OPN increased plaque inflammation and caused plaque rupture.

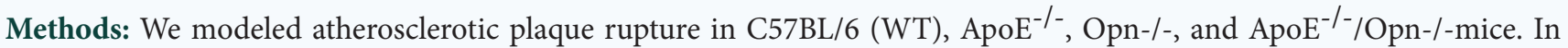
addition, we neutralized $\mathrm{N}$-half $\mathrm{OPN}$ formation in $\mathrm{ApoE}^{-/-}$mice by intraperitoneal administration of anti-N-half $\mathrm{OPN}$ antibody (M5Ab).

Results: The incidence of plaque rupture in $\mathrm{ApoE}^{-/-} / \mathrm{Opn}-/-$ mice was significantly lower than that in $\mathrm{ApoE}^{-/-}$mice $(25 \%$ and $67 \%$, respectively). Similarly, treatment with $\mathrm{M} 5 \mathrm{Ab}$ reduced the incidence of plaque rupture in ApoE ${ }^{-/-}$mice from $67 \%$ to $29 \%$. Macrophages infiltrated the plaque lesions in $\mathrm{ApoE}^{-/-}$mice, whereas, such infiltration was clearly attenuated in $\mathrm{ApoE}^{-/-} / \mathrm{Opn}-/-$ mice and inApoE $\mathrm{E}^{-/-}$mice treated with $\mathrm{M} 5 \mathrm{Ab}$.

Conclusion: In addition to the full-length OPN, the N-terninal fragment of OPN is also a key mediator of atherosclerotic plaque rupture that is capable of inducing macrophage infiltration in plaque lesions.

Keywords: Osteopontin, Thrombin cleaved osteopontin, Plaque rupture, ApoE knockout mouse

C 2018 The Authors. Published by the JScholar under the terms of the Creative Commons Attribution License http://creativecommons.org/licenses/by/3.0/, which permits unrestricted use, provided the original author and source are credited. 


\section{Introduction}

Atherosclerosis is a result of chronic inflammation of artery walls. The natural tendency of a stable plaque to transform into an unstable plaque is associated with higher risk of rupture and thrombosis, which is considered as a key mechanism of acute coronary syndrome and cerebral infarction. Plaque stability is determined by many factors, including presence of lipid deposits, oxidative stress, inflammation, and extracellular matrix degradation [1-3]. The activation of macrophages in atherosclerotic plaques leads to the secretion of inflammatory cytokines and proteolytic enzymes capable of degrading the extracellularmatrix. Thesechangesincreaseplaquevulnerability. Osteopontin (OPN) has been recognized as a significant component of the atherosclerotic inflammatory milieu and a potential plasma inflammatory marker. OPN is an extracellular matrix protein, and it is considered as a multifunctional cytokine that potently enhances atherosclerotic inflammatory reaction $[4,5]$ Bruemmer et al. reported that angiotensin IIinduced aortic plaque and aneurysm formation was attenuated in OPN-deficient mice [5]. Pedersen et al. reported that uremia induced by $5 / 6$ nephrectomy increased surface plaque area in the aortic arch in apolipoprotein E (ApoE) knockout mice and that those changes were attenuated by OPN deficiency [6]. From the clinical perspective, we previously reported that OPN is an independent determinant of mean carotid intima-media thickness (mIMT) in patients with essential hypertension [7]. These reports collectively suggested that OPN plays a major role in the development of atherosclerosis and plaque formation.

OPN is cleaved by thrombin into several secreted peptide fragments [8]. The N-terminal fragment of thrombin-cleaved OPN (N-half OPN) is also known as an inflammatory cytokine. Neoangiogenesis is a source of intraplaque hemorrhage and macrophage infiltration; it triggers plaque instability, there by increasing the risk for cardiovascular events [9]. In this setting, OPN may be cleaved by thrombin derived from new vessels in unstable plaques, resulting in the formation of $\mathrm{N}$-half OPN.

OPN contains an RGD motif [10] that is retained by N-half OPN. However, unlike OPN, N-half OPN contains an adhesive sequence, SLAYGLR, which is recognized by $\alpha_{9} \beta_{1}$ integrin [11]. N-half OPN promotes cell adhesion, [12] cell differentiation, [13] and angiogenesis [14] through $\alpha_{9} \beta_{1}$ or $\alpha_{v} \beta_{3}$ integrin signaling. Wolak et al. suggested a positive correlation between the extent of infiltration of inflammatory cells and $\mathrm{N}$-half OPN expression in human carotid plaques [15]. We previously demonstrated that plasma levels of N-half OPN were elevated after carotid artery stenting [16]. However, the role of OPN cleavage that leads to N-half OPN formation in vulnerable atherosclerotic plaques is poorly understood.
Recently, carotid artery ligation and cuff placement was shown to be a simple and highly efficient method of inducing plaque rupture in $\mathrm{ApoE}^{-/}$mice [17]. Using this model, we have reported with that deletion of angiotensin II typela receptor prevented atherosclerotic plaque rupture in $\mathrm{ApoE}^{-/-}$mice [18]. In this study, we used this murine model to examine the hypothesis that $\mathrm{N}$-half OPN increased plaque inflammation and caused plaque rupture.

\section{Methods}

\section{Animals}

The animal use protocol was approved by the Animal Studies Committee of the Ehime University. We followed animal experimentrules of the Advanced ResearchSupportCenter ofthe Ehime University. Seven-weeks-old C57BL/6 wild-type (WT) male mice were purchased from Charles River Laboratories Japan Inc. ApoE ${ }^{-/-}$mice with $\mathrm{C} 57 \mathrm{BL} / 6$ background were also purchased from Charles River Laboratories Japan Inc., whereas osteopontin knockout (Opn-/-) mice with C57BL/6 background were kindly provided by Honorary Professor ToshimitsuUede (Hokkaido University, Japan). We also generated $\mathrm{ApoE}^{-/-} / \mathrm{Opn}-/$-double knockout mice from crosses of $\mathrm{ApoE}^{-/-}$andOpn-/-mice and confirmed their genotype by PCR as described previously [19]. Nine-weeks-old male C57BL/6 WT and age-matched male ApoE ${ }^{-/-}, \mathrm{Opn}-/-$, and $\mathrm{ApoE}^{-/-} / \mathrm{Opn}-/-$ mice were used in the present study. All mice were housed in a room with a 12-h light/12-h dark cyclewith room temperature maintained at $24^{\circ} \mathrm{C}$. All mice were fed with a standard commercial diet throughout the duration of the study.

\section{Murine model of atherosclerotic plaque rupture}

We generated a murine model of atherosclerotic plaque rupture as previously reported [17]. In brief, 9-week-old mice were anesthetized with pentobarbital sodium $(50 \mathrm{mg} / \mathrm{kg}$, intraperitoneal injection) and their common carotid arteries were ligated just proximal to the bifurcation. Four weeks after the ligation, a polyethylene cuff (length: $2 \mathrm{~mm}$; inside and outside diameter: $0.580 \mathrm{~mm}$ and $0.965 \mathrm{~mm}$, respectively; IMG Imamura Co. Ltd., Tokyo, Japan) was placed around the common carotid artery just proximal to the ligated site. The intracuff lesions were collected four days after cuff placement and fixed in $10 \%$ formalin, followed by embedding in paraffin for evaluation. At the end of the study, blood samples were obtained from the inferior vena cava. 


\section{Results}

On days 25, 28, and 31after the ligation surgery, M5Ab, a neutralization antibody against mice-N-half OPN(35B6-Ab; Gene Techno Science Co. Ltd., Hokkaido, Japan) that recognizes the GDSLAYGLR epitope was administered by intraperitoneal injection to $\mathrm{ApoE}^{-/-}$mice at a dose of $400 \mu \mathrm{g} /$ mouse according to the manufacturer's protocol. The experimental protocol is shown in (Figure1).

\section{Measurement of blood pressure}

Systolic blood pressure (SBP) was measured using indirect tail-cuff method with anon-invasive blood pressure monitor (MK-2000; Muromachi Kikai, Tokyo, Japan).

\section{Biochemical measurements}

Blood samples were sent to Nagahama LSL (Shiga, Japan) for the determination of serum levels of total cholesterol (TC) and low-density lipoprotein cholesterol (LDL-C).

\section{Morphological analysis and immunohistochemistry}

The intracuff lesions were evaluated using hematoxylin and eosin ( $\mathrm{H} \& \mathrm{E})$ staining. Using $\mathrm{H} \& \mathrm{E}$ staining, cracks in the neointima and intraplaque hemorrhage identified plaque ruptures at the intracuff region of the carotid artery. The incidence of plaque rupture was expressed as percentage values of incidences/cases.

Immunohistochemical staining was performed using Simple Stain kits (Nichirei Biosciences Inc., Tokyo, Japan) according to the manufacturer's instructions. Briefly, deparaffinized sections were treated for 15 min with $3 \% \mathrm{H}_{2} \mathrm{O}_{2}$ solution in methanol to inactivate endogenous peroxidases. The sections were then incubated at room temperature for $1 \mathrm{~h}$ with primary antibodies against rat anti-F4/80 (1:500 dilution, BMA Biomedicals, Augst, Switzerland), rabbit anti-VCAM-1 (1:100 dilution, Abcam plc, United Kingdom) or rabbit anti-MCP-1 (1:100 dilution, Abcam plc, United Kingdom). Each stained section was scanned using Image J software (http:// rsb.info.nih.gov/ij/), and the ratio of positively stained area to total area (excluding the thrombusarea) was calculated and expressed as a percentage value.

\section{Statistical analysis}

Data are expressed as the mean \pm standard error of the mean. For multiple comparisons, statistical analysis was performed by one-way analysis of variance and post hoc Scheffe's test. For categorical variables, groups were compared using chi-squared test. Differences were considered to be statistically significant if $\mathrm{P}<0.05$.

\section{Biological parameters of atherosclerotic plaque rupture model mice}

We examined plasma lipid status and blood pressure level as these parameters are implicated in plaque vulnerability. There were no significant differences in plasma TC between $\mathrm{ApoE}^{-}$ /- and $\mathrm{ApoE}^{-/-} / \mathrm{Opn}-/-$ mice $(379.0 \pm 21.5 \mathrm{mg} / \mathrm{dL}$ and $452.7 \pm$ $88.9 \mathrm{mg} / \mathrm{dL}$, respectively; $\mathrm{n}=3$ for each group) or LDL-C (344.6 $\pm 20.2 \mathrm{mg} / \mathrm{dL}$ and $430.6 \pm 80.6 \mathrm{mg} / \mathrm{dL}$, respectively; $\mathrm{n}=3$ for each group). Likewise, there were no differences in baseline

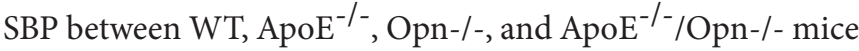
(99.7 $\pm 8.5 \mathrm{mmHg}, 109.6 \pm 8.7 \mathrm{mmHg}, 97.5 \pm 3.3 \mathrm{mmHg}$, and $102.7 \pm 6.0 \mathrm{mmHg}$, respectively; $\mathrm{P}>0.05 ; \mathrm{n}=3$ for each group).

\section{Effect of OPN and N-half OPN on atherosclerotic plaque rupture}

To test the effects of OPN and N-half OPN on atherosclerotic plaque rupture, we performed carotid artery ligation and subsequent cuff placement in wild type, $\mathrm{ApoE}^{-/-}$, Opn-/-, and ApoE $\mathrm{E}^{-/-} / \mathrm{Opn}-/-$ mice. Neointima formation was induced by four weeks of carotid artery ligation, but no intraplaque hemorrhage or plaque rupture was observed. At four days after cuff placement, several morphological changes, including intraplaque hemorrhage, neointima cracks, and thrombus formation were observed in the lumen. A representative carotid artery plaque rupture is shown in Figure 2A. Plaque rupture in wild type and Opn-/- mice was observed in $17 \%$ cases in both groups (i.e., in 2 out of 12 mice for each group; (Figure 2B). In $\mathrm{ApoE}^{-/-}$mice, however, the incidence of plaque rupture with thrombus was significantly higher $(67 \%, n=12$, (Figure $2 B$ ). In $\mathrm{ApoE}^{-/-} / \mathrm{Opn}-/-$ mice, the incidence of plaque rupture was significantly lower than in $\mathrm{ApoE}^{-/-}$mice $(25 \%, \mathrm{n}=12$, Figure 2B). ApoE $\mathrm{E}^{-/-}$mice treated with $\mathrm{M} 5 \mathrm{Ab}$ had a nominally lower rate of plaque rupture $(29 \%, \mathrm{n}=7)$ than untreated $\mathrm{ApoE}^{-/-}$ mice, but the difference did not achieve statistical significance. At the same time, incidence of plaque rupture in M5Ab-treated $\mathrm{ApoE}^{-/-}$mice was not statistically different from that in $\mathrm{ApoE}^{-}$ /-/Opn-/- mice (Figure 2B).

The neointima area in WT mice was $22.2 \pm 6.6 \times 10^{3} \mu \mathrm{m}^{2}(\mathrm{n}=$ 7) and in Opn-/-mice, it was $17.2 \pm 4.5 \times 10^{3} \mu \mathrm{m}^{2}(\mathrm{n}=7$ ) (Figure 2C).In untreated $\mathrm{ApoE}^{-/-}$mice, the neointima area was significantly larger $\left(62.22 .7 \times 10^{3} \mu \mathrm{m}^{2} ; \mathrm{n}=7\right)$ than in $\mathrm{ApoE}^{-/-}$ Opn-/-mice $\left(32.8 \pm 1.5 \times 10^{3} \mu \mathrm{m}^{2} ; \mathrm{n}=7 ; \mathrm{P}<0.05\right)$ or in $\mathrm{ApoE}^{-}$ /- mice treated with M5Ab $\left(33.2 \pm 5.3 \times 10^{3} \mu \mathrm{m}^{2} ; \mathrm{n}=7 ; \mathrm{P}<0.05\right.$; (Figure 2C). 


\section{Macrophage infiltration in plaque rupture model}

Inflammation plays a central role in atherosclerosis, and therefore, we evaluated macrophage infiltration in plaques by immunohistochemical staining for F4/80, a specific murine macrophage marker. F4/80-positive areas were observed in ApoE ${ }^{-/-}$mice $(9.3 \pm 0.7 \%, n=5$ ) (Figure 3A-b, 3B). In contrast, these areas were clearly smaller in $\mathrm{ApoE}^{-/-} / \mathrm{Opn}-/-$ mice (3.1 $\pm .3 \%, \mathrm{n}=5, \mathrm{P}<0.05$ ) (Figure $3 \mathrm{~A}-\mathrm{c}, 3 \mathrm{~B}$ ) and in $\mathrm{ApoE}^{-/-}$ mice treated with $\mathrm{M} 5 \mathrm{Ab}(1.6 \pm 0.2 \%, \mathrm{n}=5, \mathrm{P}<0.05)$ (Figure 3A-d,3B).

\section{VCAM-1 and MCP-1 expression in plaque rupture model and effect of M5Ab}

Next, we examined that which molecular contributed to macrophages infiltration in the downstream of OPN and N-half OPN. At first, we analyzed vascular cell adhesion molecule-1
(VCAM-1), which is an important adhesion molecule for monocyte. We found VCAM-1-positive area was expanded in $\mathrm{ApoE}^{-/-}$mice $(5.7 \pm 0.9 \%$ ) (Figure 4A-b, 4B). In contrast, these changes were clearly attenuated in $\mathrm{ApoE}^{-/-} \mathrm{OPN}^{-/-}$mice $(0.23 \pm 0.1 \%, \mathrm{p}<0.05)$ (Figure $4 \mathrm{~A}-\mathrm{c}, 4 \mathrm{~B}$ ) and $\mathrm{ApoE} \mathrm{E}^{-/-}+\mathrm{M} 5 \mathrm{Ab}$ mice $(1.3 \pm 0.2 \%, \mathrm{p}<0.05)$ (Figure $4 \mathrm{~A}-\mathrm{d}, 4 \mathrm{~B})$. In previous study, MCP-1, Monocyte Chemotactic Protein-1, was reported as a key mediator of macrophage infiltrating to tissue in the downstream of OPN, [20]. We examined MCP-1 expression using immunohistochemical staining. However, there was no difference in expression among between $\mathrm{ApoE}^{-/-}$mice, $\mathrm{ApoE}^{-}$ /- $\mathrm{OPN}^{-/-}$mice, and ApoE ${ }^{-/-}+\mathrm{M} 5 \mathrm{Ab}$ mice (Figure 4C).

\section{Figure 1}

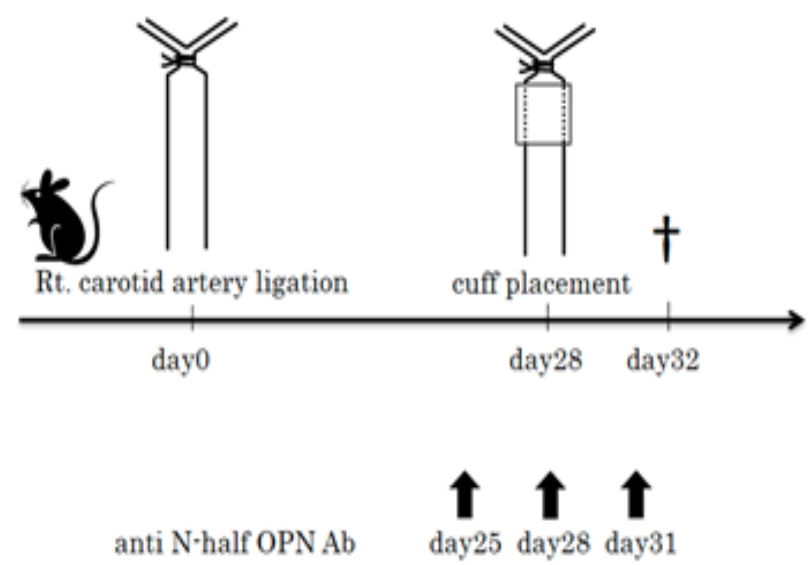

Figure 1: Experimental protocol of the present in vivo study 
Figure 2

A)

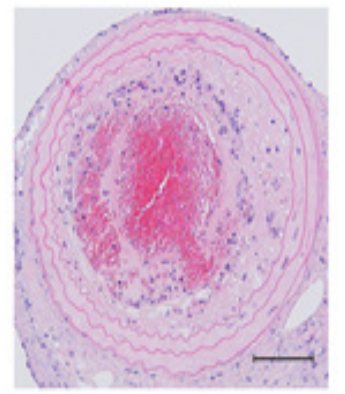

B)

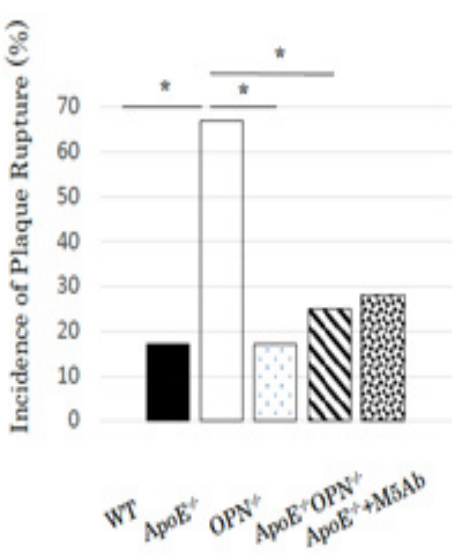

C)

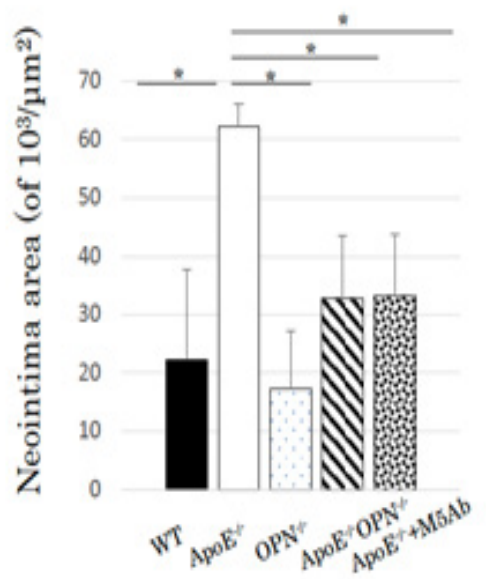

Figure 2. Plaque rupture and neointimal area

A) A representative carotid artery plaque rupture stained with hematoxylin and eosin. Several typical morphological changes, including intraplaque hemorrhage, cracks of neointima, and thrombus formation in the lumenare observed. Scale bar, 100 $\mu \mathrm{m}$.

B) Incidence of plaque rupture was determined in wild type $(\mathrm{n}=12)$, ApoE-/- $(\mathrm{n}=12)$, Opn-/-(n=12), ApoE $\mathrm{E}^{-/-/ O p n-}$ /- $(\mathrm{n}=12)$ mice, and in ApoE-/- animals treated with M5Ab $(\mathrm{n}=7)$. The incidence of plaque rupture with thrombus in ApoE-/- mice was significantly higher than in wild type animals. In $\mathrm{ApoE}^{-/-} / \mathrm{Opn}-/$-mice, the incidence of plaque rupture was significantly lower than in ApoE-/- mice and similar to that observed inApoE-/- mice treated with M5Ab.Statistical significance is indicated as follows: ${ }^{*} \mathrm{P}<0.05$ (for categorical variables, groups were compared using a chi-squared test).

C) Neointima area was measured in wild type, $\mathrm{ApoE}^{-/-}, \mathrm{Opn}-/-, \mathrm{ApoE}^{-/-} / \mathrm{Opn}-/-$ mice, and in $\mathrm{ApoE}^{-/-}$animals treated with $\mathrm{M} 5 \mathrm{Ab}$. Neointima area in $\mathrm{ApoE}^{-/}$-mice was significantly larger than in all other groups $(\mathrm{P}<0.05)$, whereas no other intergroup differences were observed. Data are presented the mean \pm standard error of the mean. $n=7$ in each group. Statistical significance is indicated as follows: ${ }^{*} \mathrm{P}<0.05$ (one-way analysis of variance followed by post hoc Scheffe's test). 
Figure 3

A)
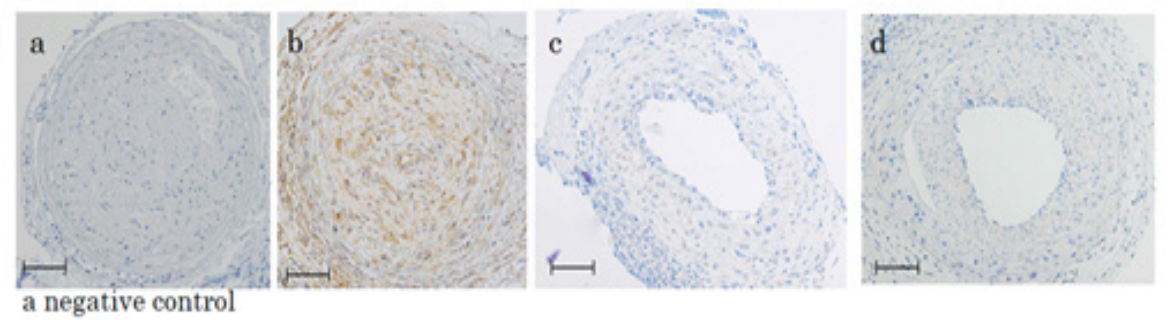

b ApoE

$\mathrm{CApoE} / \mathrm{OPN}$

$\mathrm{d} \mathrm{ApoE}^{-}+\mathrm{M} 5 \mathrm{Ab}$

B)

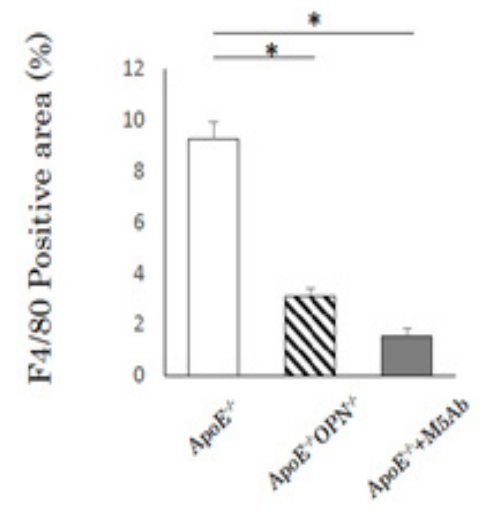

Figure 3: Immunohistochemistry by anti-F4/80

A) Representative images of F4/80-positive expression in $\mathrm{ApoE}^{-/-}$(b), $\mathrm{ApoE}^{-/-} / \mathrm{Opn}-/-$ (c), and $\mathrm{ApoE}^{-/-}+\mathrm{M} 5 \mathrm{Ab}$ (d) groups. (a) negative control.

B) Plot of F4/80-positive area in samples from $\mathrm{ApoE}^{-/-}, \mathrm{ApoE}^{-/-} / \mathrm{Opn}-/-$, and $\mathrm{ApoE}^{-/-}+\mathrm{M} 5 \mathrm{Ab}$ groups. Note the significantly higher $\mathrm{F} 4 / 80$ levels in untreated $\mathrm{ApoE}^{-/-}$mice. Data are presented the mean \pm standard error of the mean. $\mathrm{n}=5$ in each group. Statistical significance is indicated as follows: ${ }^{*} \mathrm{P}<0.05$ (one-way analysis of variance followed by post hoc Scheffe's test). Scale bar, $100 \mu \mathrm{m}$.

\section{Discussion}

\section{Roles of OPN and N-half OPN on atherosclerotic plaque rupture}

In this study, we showed that OPN and N-half OPN play critical roles in atherosclerotic plaque vulnerability and continuous plaque rupture. Our hypothesis was that N-half OPN, the thrombin-cleaved OPN, activated the inflammation of atherosclerotic plaque and induced plaque rupture. If this hypothesis was correct, OPN knockout and neutralization of $\mathrm{N}$-half OPN could be expected to have equivalent reducing effects on plaque rupture incidence. However, the effect of
OPN knockout on inhibition of plaque rupture was higher than that of M5Ab treatment. This was reasonable, because OPN in plaques may not be completely converted to N-half OPN. We first showed that induction of plaque rupture stimulated the cleavage of OPN into N-half OPN, and therefore, it may be presumed that OPN plays an important role in plaque rupture formation. In a recent clinical study, Wolak et al. investigated 41 patients who underwent carotid endarterectomy and exhibited plaques that were categorized to possess high- and low-grade inflammation based on their histological features [15]. Analysis of OPN and N-half OPN levels in these plaques by western blotting showed that highgrade inflammation plaques had a greater content of N-half 
Figure 4

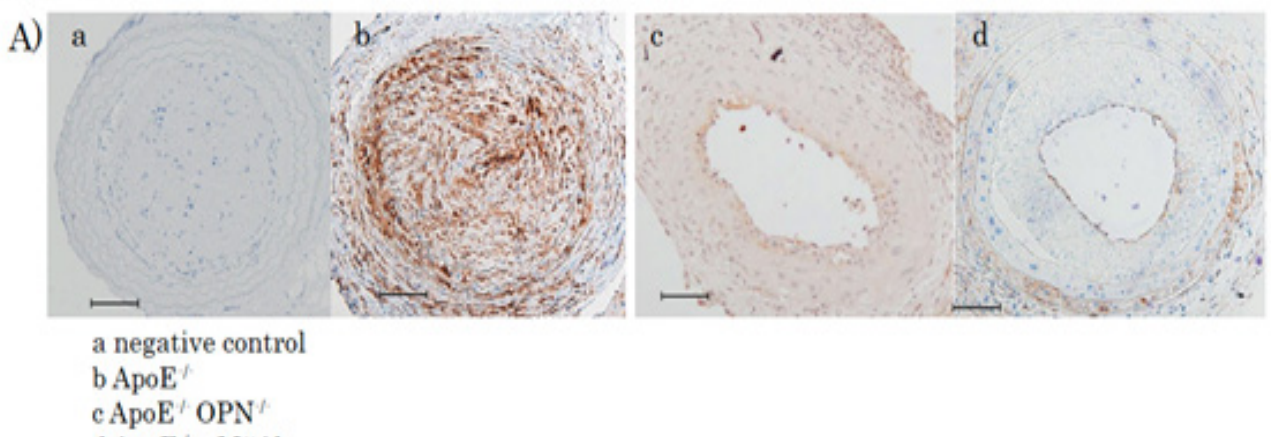

$\mathrm{d} \mathrm{ApoE}+\mathrm{M} 5 \mathrm{Ab}$

B)

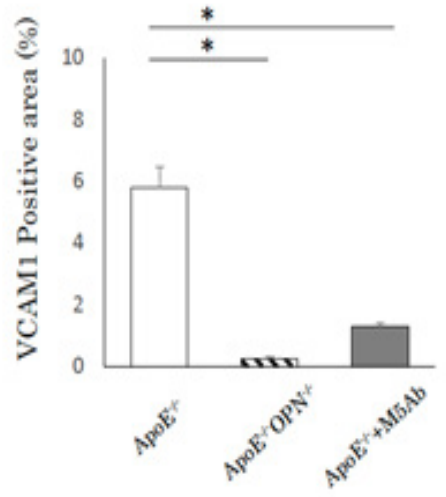

(C)

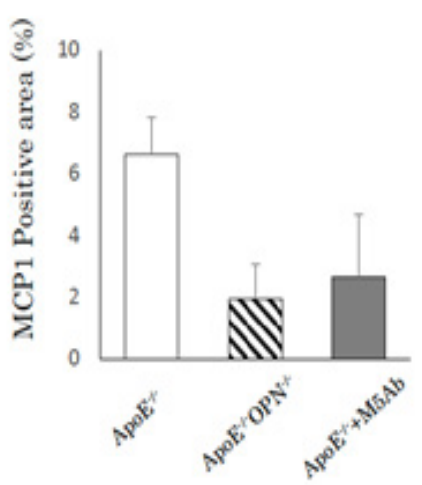

Figure 4:Immunohistochemistry by anti-VCAM-1

A) Representative images of VCAM-1 expression in $\mathrm{ApoE}^{-/-}$(b), $\mathrm{ApoE}^{-/-} / \mathrm{Opn}-/-(\mathrm{c})$, and $\mathrm{ApoE} \mathrm{E}^{-/-}+\mathrm{M} 5 \mathrm{Ab}$ (d) groups are illustrated.(a) negative control.(B) Plot of VCAM-1-positive area in samples from ApoE $E^{-/-}, \mathrm{ApoE}^{-/-} / \mathrm{Opn}^{-/-}$, and ApoE $\mathrm{A}^{-/-}+$ $\mathrm{M} 5 \mathrm{Ab}$ groups. Note the significantly higher VCAM-1 expressionin untreated $\mathrm{ApoE}^{-/-}$mice. Data are presented the mean \pm standard error of the mean. $\mathrm{n}=5$ in each group. Statistical significance is indicated as follows: ${ }^{*} \mathrm{P}<0.05$ (one-way analysis of variance followed by post hoc Scheffe's test). (C) Plot of MCP1-positive area in samples from ApoE ${ }^{-/-}, \mathrm{ApoE}^{-/-} / \mathrm{Opn}^{-/-}$, and $\mathrm{ApoE}^{-/-}+\mathrm{M} 5 \mathrm{Ab}$ groups. Data represent the mean \pm standard error of the mean. $\mathrm{n}=5$ in each group. (one-way analysis of variance followed by post hoc Scheffe's test). Scale bar $100 \mu \mathrm{m}$.

OPN than low-grade inflammation plaques. In contrast, OPN levels were similar in low- and high-degree inflammation plaques. We also previously demonstrated that plasma N-half OPN level was elevated after carotid artery stenting in patients who had undergone acute atherothrombotic ischemic stroke [16]. Based on these studies, we propose that N-half OPN plays a critical role in atherosclerotic plaque rupture.

\section{Roles of OPN and N-half OPN on neointimal formation}

OPN deficiency and neutralization of N-half OPN activity inhibited not only plaque rupture but also neointima area formation. Therefore, lower incidence of plaque rupture in ApoE $\mathrm{E}^{-/-} / \mathrm{Opn}-/$-mice and in $\mathrm{ApoE}^{-/-}$mice treated with M5Ab could be explained by the fact that neointima areas in these animals was significantly narrower than in untreated $\mathrm{ApoE}^{-}$ /-mice. These results indicated that not only OPN, but also $\mathrm{N}$-half OPN, promoted cell proliferation and migration activity in smooth muscle cells. Liaw et al reported that OPN mediates vascular smooth muscle cell migration via interaction with cell surface integrin $\alpha_{\mathrm{v}} \beta_{3}$ that recognizes the RGD sequence [21]. 
Macrophage activation by OPN and N-half OPN

OPN has two integrin-binding motifs, RGD and SLAYGLR. The latter motif is revealed in N-half OPN only after thrombin cleavage, [22] and it functions as a ligand for integrin $\alpha_{9} \beta_{1}$, $\alpha_{4} \beta_{1}$, and $\alpha_{4} \beta_{7}$. [23]. These integrins are expressed in activated macrophages where they stimulate further production of inflammatory cytokines and chemokines [23]. We therefore evaluated macrophage infiltration in the plaque rupture model and observed that the number of F4/80-positive macrophages was markedly increased in $\mathrm{ApoE}^{-/-}$mice. OPN deficiency and $\mathrm{M} 5 \mathrm{Ab}$ treatment significantly attenuated macrophage infiltration inplaques, indicating that both OPN and N-half OPN are key chemoattractants of macrophages in atherosclerotic plaque. Increased neovascularization is an important contributing factor to plaque vulnerability. Kale et al. reported that OPN activates macrophages and influences angiogenesis by enhancing cyclooxygenase-dependent prostaglandin E2 production via $\alpha_{9} \beta_{1}$ integrin [24]. Matrix metalloproteinase (MMP) degrades the major components of the vascular extracellular matrix, including the fibrous cap of the atherosclerotic plaque [3]. OPN has been reported to enhance adventitial myofibroblast and vascular smooth muscle cell migration and proliferation and promote activation of vascular MMP-2 and MMP-9 [25]. Lai et al. reported that OPN and the peptide SVVYGLR activated pro MMP-9 and enhanced oxidative stress in aortic smooth muscle cells in vivo and in vitro [26]. These previous reports suggested that OPN and $\mathrm{N}$-half $\mathrm{OPN}$ increase plaque vulnerability and rupture by activating MMPs and inducing neovascularization.

\section{Relationship between OPN and N-half OPN and adhesion molecules}

Next, we asked which adhesion molecules contributed to macrophage infiltration downstream of OPN and N-half OPN. We focused on VCAM-1 and MCP-1 expression in our model. VCAM-1 is expressed both in endothelial cells and the neointimal area. Previous reports indicated that induction of endothelial-mesenchymal transition in endothelial cells upregulates mesenchymal markers, smooth muscle marker, and leukocyte adhesion molecules such as VCAM-1 both in endothelial cells and in the neointimal area. VCAM-1 promotes influx of inflammatory cells in atherosclerotic plaques and enhances the deposition of extracellular matrix, appearance of new mesenchymal cells in the neointima, and plaque expansion $[28,29]$. As shown in Figure 4, VCAMlexpression in $\mathrm{ApoE}^{-/-} / \mathrm{Opn}-/$-mice and in $\mathrm{ApoE}^{-/-}$mice treated with $\mathrm{M} 5 \mathrm{Ab}$ was lower than in untreated $\mathrm{ApoE}^{-/-}$ mice, which is in agreement with the results of Bruemmer et al. In contrast, MCP-1 levels did not differ among the three groups. According to these results, VCAM-1 is an important chemoattractant that stimulates macrophage infiltration in plaques. Infiltration of macrophages causes further inflammation in atherosclerotic plaques and leads to secretion of inflammatory cytokines. This, in turn, leads to neovascularization and activation of proteolytic enzymes capable of degrading the extracellular matrix, i.e., the changes that increase plaque vulnerability. However, we just examined the MCP-1 and VCAM-1 expression levels. Therefore, further functional study is needed.

\section{Thrombin inhibitor and atherosclerosis}

Recently, several groups reported that thrombin inhibition by dabigatran attenuates atherosclerosis ${ }^{30}$ and atherosclerotic lesion instability [31]. These findings prompted us to hypothesize that the anti-atherosclerotic effect of dabigatran may at least partly derive from the attenuation of OPN cleavage by thrombin, which would negatively affect N-half OPN formation.

\section{Limitations}

However, this study has few limitations. First, this study was performed in a mouse model of atherosclerotic plaque rupture that mimics only some aspects of the human disease. Second, we did not measure plasma lipid status and blood pressure in mice treated with M5Ab. Third, we did not completely distinguish the functional differences between full length OPN and N-half OPN. Fourth, we could not show the source of OPN and N-half OPN.

\section{Conclusion}

The present study in experimental mice demonstrated that $\mathrm{N}$-half OPN may be a key mediator of atherosclerotic plaque vulnerability. N-half OPN inhibition decreased infiltration of macrophages to plaques via increased VCAM-1 expression. $\mathrm{N}$-half OPN may therefore be a potential target for therapeutic interventions aimed at stabilizing plaques and preventing their rupture.

\section{Sources of funding}

This work was supported in part by a Grant-in-Aid for Scientific Research (C) to Dr Okura (No. 16K09643) from the Ministry of Education, Culture, Sports, Science and Technology, Japan. 


\section{Acknowledgment of support}

We are grateful to Dr. Uede who kindly provided us with Opn-/- mice. We would also like to thank Gene Techno Science Co., Ltd. for M5 antibody.

\section{References}

1. Richardson PD, Davies MJ, Born GV (1989) Influence of plaque configuration and stress distribution on fissuring of coronary atherosclerotic plaques. Lancet 2:941-944.

2. van der Wal AC, Becker AE, van der Loos CM, Das PK (1994) Site of intimal rupture or erosion of thrombosed coronary atherosclerotic plaques is characterized by an inflammatory process irrespective of the dominant plaque morphology. Circulation 89:36-44.

3. Rajagopalan S, Meng XP, Ramasamy S, Harrison DG,Galis ZS (1996) Reactive oxygen species produced by macrophagederived foam cells regulate the activity of vascular matrix metalloproteinases in vitro. Implications for atherosclerotic plaque stability. J Clin Invest 98:2572-2579.

4. Chiba S, Okamoto H, Kon S, Kimura C, Murakami M, et al. (2002) Development of atherosclerosis in osteopontin transgenic mice. Heart Vessels16:111-117.

5. Bruemmer D, Collins AR, Noh G, Wang W, Territo M, et al. (2003) Angiotensin II-accelerated atherosclerosis and aneurysm formation is attenuated in osteopontin-deficient mice. J Clin Invest 112:1318-1331.

6. Pedersen TX, Madsen M, Junker N, Christoffersen C, Vikesa J, et al. (2013) Osteopontin deficiency dampens the proatherogenic effect of uraemia. Cardiovasc Res 98:352-359.

\section{Kurata M, Okura T, Watanabe S, Fukuoka T,Higaki J (2006)} Osteopontin and carotid atherosclerosis in patients with essential hypertension. ClinSci (Lond) 111:319-324.

8. Kon S, Maeda M, Segawa T, Hagiwara Y, Horikoshi Y, et al. (2000) Antibodies to different peptides in osteopontin reveal complexities in the various secreted forms. J Cell Biochem 7:487-498.

9. O'Brien ER, Garvin MR, Dev R, Stewart DK, Hinohara T, et al. (1994) Angiogenesis in human coronary atherosclerotic plaques. Am J Pathol 145:883-894.

10. Flores ME, Norgard M, Heinegard D, Reinholt FP, Andersson G (1992) RGD-directed attachment of isolated rat osteo- clasts to osteopontin, bone sialoprotein, and fibronectin. Exp Cell Res 201:526-530.

11. Smith LL, Cheung HK, Ling LE, Chen J, Sheppard D, et al. (1996) Osteopontin N-terminal domain contains a cryptic adhesive sequence recognized by alpha9betal integrin. J BiolChem 271:28485-28491.

12. Ito K, Kon S, Nakayama Y, Kurotaki D, Saito Y, et al. (2009) The differential amino acid requirement within osteopontin in alpha4 and alpha9 integrin-mediated cell binding and migration. Matrix Biol 28:11-19.

13. Uchinaka A, Hamada Y, Mori S, Miyagawa S, Saito A, et al. (2015) SVVYGLR motif of the thrombin-cleaved N-terminal osteopontin fragment enhances the synthesis of collagen type III in myocardial fibrosis. Mol Cell Biochem 408:191-203.

14. Senger DR, Ledbetter SR, Claffey KP, Papadopoulos-Sergiou A, Peruzzi CA, et al. (1996) Stimulation of endothelial cell migration by vascular permeability factor/vascular endothelial growth factor through cooperative mechanisms involving the alphavbeta3 integrin, osteopontin, and thrombin. Am J Pathol 149:293-305.

15. Wolak T, Sion-Vardi N, Novack V, Greenberg G, Szendro G, et al. (2013) N-terminal rather than full-length osteopontin or its C-terminal fragment is associated with carotidplaque inflammation in hypertensive patients. Am J Hypertens 26:326-333.

16. Kurata M, Okura T, Kumon Y, Tagawa M, Watanabe H, et al. (2012) Plasma thrombin-cleaved osteopontin elevation after carotid artery stenting in symptomatic ischemic stroke patients. Hypertens Res 35:207-212.

17. Sasaki T, Kuzuya M, Nakamura K, Cheng XW, Shibata T, et al. (2006) A simple method of plaque rupture induction in apolipoprotein E-deficient mice. Arterioscler Thromb Vasc Biol 26:1304-1309.

18. Aono J, Suzuki J, Iwai M, Horiuchi M, Nagai T,et al. (2012) Deletion of the angiotensin II type 1a receptor prevents atherosclerotic plaque rupture in apolipoprotein E-/- mice. Arterioscler Thromb Vasc Biol 32:1453-1459.

19. Pei Z, Okura T, Nagao T, Enomoto D, Kukida M, et al. (2016) Osteopontin deficiency reduces kidney damage from hypercholesterolemia in Apolipoprotein E-deficient mice. Sci Rep 6:28882. 
20. Zheng W, Li R, Pan H, He D, Xu R, et al. (2009) Role of osteopontin in induction of monocyte chemoattractant protein 1 and macrophage inflammatory protein 1 beta through the NF-kappa B and MAPK pathways in rheumatoid arthritis. Arthritis Rheum 60:1957-1965.

21. Liaw L, Skinner MP, Raines EW, Ross R, Cheresh DA, et al. (1995) The adhesive and migratory effects of osteopontin are mediated via distinct cell surface integrins. Role of alpha $\mathrm{v}$ beta 3 in smooth muscle cell migration to osteopontin in vitro. J Clin Invest 95:713-724.

22. Nishimichi N, Higashikawa F, Kinoh HH, Tateishi Y, Matsuda H, et al. (2009) Polymeric osteopontin employs integrin alpha 9 betal as a receptor and attracts neutrophils by presenting a de novo binding site. J BiolChem 284:14769-14776.

23. Lund SA, Wilson CL, Raines EW, Tang J, Giachelli CM, et al. (2013) Osteopontin mediates macrophage chemotaxis via alpha4 and alpha9 integrins and survival via the alpha4 integrin. J Cell Biochem114:1194-1202.

24. Kale S, Raja R, Thorat D, Soundararajan G, Patil TV, et al.(2014) Osteopontin signaling upregulates cyclooxygenase-2 expression in tumor-associated macrophages leading to enhanced angiogenesis and melanoma growth via alpha9 beta1 integrin. Oncogene 33:2295-2306.

25. Krishnamurthy P, Peterson JT, Subramanian V, Singh M, Singh K (2009) Inhibition of matrix metalloproteinases improves left ventricular function in mice lacking osteopontin after myocardial infarction. Mol Cell Biochem322:53-62.

26. Lai CF, Seshadri V, Huang K, Shao JS, Cai J,et al. (2006) An osteopontin-NADPH oxidase signaling cascade promotes pro-matrix metalloproteinase 9 activation in aortic mesenchymal cells. Circ Res 98:1479-1489.

27. Chen PY, Qin L, Baeyens N, Li G, Afolabi T, et al. (2015) Endothelial-to-mesenchymal transition drives atherosclerosis progression. J Clin Invest 125:4514-4528.

28. Manka DR, Wiegman P, Din S, Sanders JM, Green SA, et al. (1999) Arterial injury increases expression of inflammatory adhesion molecules in the carotid arteries of apolipoprotein-E-deficient mice. J Vasc Res 36:372-378.

29. Pingel S, Tiyerili V, Mueller J, Werner N, Nickenig G, et al. (2014) Thrombin inhibition by dabigatran attenuates atherosclerosis in ApoE deficient mice. Arch Med Sci10:154-160.
30. Kadoglou NP, Moustardas P, Katsimpoulas M, Kapelouzou A, Kostomitsopoulos N, et al. (2012) The beneficial effects of a direct thrombin inhibitor, dabigatran etexilate, on the development and stability of atherosclerotic lesions in apolipoprotein E-deficient mice: dabigatran etexilate and atherosclerosis. Cardiovasc Drugs Ther 26:367-374.

Submit your manuscript to a JScholar journal and benefit from:

ब Convenient online submission

- Rigorous peer review

- Immediate publication on acceptance

I Open access: articles freely available online

ब High visibility within the field

- Better discount for your subsequent articles Submit your manuscript at http://www.jscholaronline.org/submit-manuscript.php 